\title{
Roberto Schwarz e a referencialidade da forma machadiana
}

\author{
Elvis Paulo Couto* \\ Universidade Estadual Paulista \\ Assis, Brasil \\ Recebido em: 27/02/2019 \\ Aceito em: 04/04/2019
}

Resumo: Este artigo objetiva investigar os pressupostos teóricos da crítica de Roberto Schwarz a Memórias póstumas de Brás Cubas, de Machado de Assis. Para isso, demonstraremos que certa experiência brasileira de interpretação sociológica da contradição entre o atraso das instituições coloniais e a modernidade do ideário liberal é capaz de esclarecer o processo dialético de formalização de dados externos operado no primeiro romance moderno brasileiro.

Palavras-chave: Forma literária. Processo social. Machado de Assis. Roberto Schwarz.

\begin{abstract}
This article aims to investigate the theoretical assumptions of Roberto Schwarz's criticism of The posthumous memories of Brás Cubas by Machado de Assis. For this, we will demonstrate that certain Brazilian experience of sociological interpretation of the contradiction between the backwardness of the colonial institutions and the modernity of liberal ideology is able to clarify the dialectical process of external data formalization operated in the first modern Brazilian novel.
\end{abstract}

Keywords: Literary form. Social process. Machado de Assis. Roberto Schwarz.

Résumé: Cet article vise à enquêter les présupposés théoriques de la critique de Roberto Schwarz sur les Mémoires posthumes de Brás Cubas, roman écrit par Machado de Assis. Pour ce faire, nous démontrerons que certaine expérience brésilienne d'interprétation sociologique de la contradiction entre le retard des institutions coloniales et la modernité de l'idéologie libéral est capable de clarifier le processus dialectique de formalisation des données externes exécuté dans le premier roman moderne brésilien.

Mots-clés: Forme littérarie. Processus social. Machado de Assis. Roberto Schwarz. 


\section{Introdução}

No conhecido ensaio "Tradition and the individual talent", T. S. Eliot (1958) afirma que o verdadeiro poeta, merecedor desse nome, é aquele que compõe versos em que se vejam, a um só tempo, a incorporação da tradição poética e o distanciamento crítico em relação a ela. Noutras palavras, é aquele que aproveita o legado das gerações precedentes e inova a partir dele, marcando a sua posição na história da literatura. Esse pensamento contém um pressuposto básico: o valor da criação literária é mensurável pela sua comparação com as obras dos escritores mortos. O paradoxo da mudança que não prescinde da conservação deve, segundo Eliot, penetrar na consciência do poeta.

Paulo Arantes (1997, p. 27) sugeriu que essa ideia eliotiana de tradição é análoga ao conceito de sistema na Formação da literatura brasileira. Nela, Antonio Candido sustenta a concepção de que o sistema literário se forma quando há a integração harmônica e funcional entre escritor, obra e público. Além disso, evidencia que todo escritor maduro é aquele que aprendeu o sentido da formação, isto é, soube localizar e corrigir as falhas presentes na herança literária de seu país, crescendo sobre os ombros de seus antepassados. Sobre Machado de Assis, o escritor que representa o período de maturidade na literatura brasileira, Candido (2007, p. 529) diz:

\footnotetext{
Na verdade, ele foi, sob vários aspectos, continuador genial, não figura isolada e literariamente sem genealogia no Brasil, tendo encontrado em Alencar, além da sociologia da vida urbana, sugestões psicológicas muito acentuadas no sentido da pesquisa profunda.
}

Note-se que a obra de Alencar foi, por assim dizer, a escola de Machado: nela ele se inspirou, mas também enxergou as fraquezas que buscou superar.

A crítica literária de Roberto Schwarz, sobretudo a que é dedicada ao estudo da obra machadiana, não se encontra desvinculada da tradição. Consciente da importância da formação, o autor levou a sério a lição de Candido 
- seu mentor intelectual - e absorveu da fortuna crítica do bruxo do Cosme Velho os aspectos que julgou positivos, dando-lhes nova fisionomia. Schwarz (1987, p. 115) diz que Augusto Meyer escreveu as "melhores páginas sobre Machado" e que foi nelas que encontrou o embrião da ideia central de sua tese sobre a Memórias póstumas de Brás Cubas. Meyer (1952, p. 13) afirma o seguinte sobre o narrador Brás Cubas: "fez do seu capricho uma regra de composição". O livro Um mestre na periferia do capitalismo: Machado de Assis é arquitetado justamente sobre a noção de que o capricho do narrador é um princípio formal. Porém, há uma diferença substancial entre os críticos: enquanto a leitura de Meyer norteia-se pela psicologia, a de Schwarz apaga o psicologismo para enfatizar o caráter de classe da narração caprichosa, daí a sua originalidade cuja gênese encontra-se na linha evolutiva dos estudos sobre Machado.

É bom frisar, portanto, que o livro Um mestre na periferia do capitalismo: Machado de Assis interpreta, sob nova perspectiva, um aspecto formal sobre o qual havia discorrido Meyer em sua obra de crítica a Memórias póstumas de Brás Cubas. Schwarz (200ob, p. 18), apoiando-se em estudos anteriores, mostrou que o discurso volúvel do narrador em primeira pessoa é a "estilização de uma conduta própria à classe dominante brasileira”. Note-se que os romances de Joaquim Manuel de Macedo e de José de Alencar retrataram o comportamento da elite, mas Machado de Assis, na visão de Schwarz (20oob, p. 31), foi o primeiro a transformar esse comportamento em forma. Trata-se de uma revolução no "plano da forma”, pois "trocam-se estilos, escolas, técnicas, gêneros, recursos gráficos", bem como

[...] a narrativa passa do trivial ao metafísico, ou vice-versa, do estrito ao digressivo, da palavra ao sinal (o capítulo à moda shandyana, feito de pontinhos, exclamações e interrogações), da progressão à marcha ré no tempo, do comercial ao bíblico, do épico ao intimista, do científico à charada, do neoclássico ao naturalista e ao chavão surrado etc. etc.

A originalidade da posição de Schwarz (20oob, p. 35) foi descortinar "o referente [...] captado e imitado nesta forma de prosa”. O autor demonstrou que o modo como Machado construiu a categoria do narrador é análogo à maneira de agir da classe dirigente brasileira. Interessou ao crítico não o que o texto diz, mas 
como diz. Haveria, portanto, afinidade entre estrutura narrativa e estrutura histórico-social. Nas palavras de Rouanet (1991, p. 177), tratando de Schwarz: "O dispositivo formal capta e estiliza a estrutura do país. [...] a volubilidade como técnica transforma-se na mimese da volubilidade como estrutura social". Para que se compreenda a perspectiva proposta por Schwarz (200ob, p. 35), é necessária, por conseguinte, a recorrência à "reflexão extraliterária" capaz de esclarecer o sentido do processo de estilização de dados externos. É por isso que ele fala em "matriz prática": foi o mundo prático, objetivo, regulado segundo o desenvolvimento do capitalismo nos países centrais, que forneceu a Machado de Assis elementos para a composição de sua obra.

A estrutura literária, mais propriamente o discurso dúctil e discricionário proferido pelo narrador, encerra o conhecimento da estrutura da sociedade brasileira. Sociedade que se emancipou politicamente no limiar do século XIX, mas manteve inalteradas as condições materiais asseguradas pelo complexo colonial: "É sabido que a emancipação política do Brasil, embora integrasse a transição para a nova ordem do capital, teve caráter conservador" (SCHWARZ, 200ob, p. 36).

Segundo Emília Viotti da Costa (2010, p. 62), os grupos elitistas julgavam a manutenção da Colônia um óbice à liberdade econômica e administrativa. Foi devido a isso que se empenharam na dissolução de sua dependência em relação à metrópole. A Independência foi motivada pela ânsia de abertura ao comércio exterior, porém as bases de produção foram conservadas. O tráfico negreiro com finalidade escravagista permaneceu incólume, pois o trabalho compulsório dos africanos garantia a sobrevivência dos privilégios da classe dominante: "As conquistas liberais da Independência alteravam o processo político de cúpula e redefiniam as relações estrangeiras, mas não chegavam ao complexo socioeconômico gerado pela exploração colonial, que ficava intacto" (SCHWARZ, 200ob, p. 36).

Luiz Felipe de Alencastro (1979, p. 417, grifo do autor) mostra que o Decreto de Abertura dos Portos (1808) - a carta régia em que Dom João VI autorizou o comércio da Colônia com as nações europeias - marcou o início do processo de expansão do sistema de plantation. A economia colonial tornou-se 
robusta e não interessava mais às classes proprietárias o prolongamento dos vínculos tributários com a Coroa portuguesa: "Pour utiliser des concepts courants, les événements qui se déroulent entre 1808 et 1850 illustrent la transformation

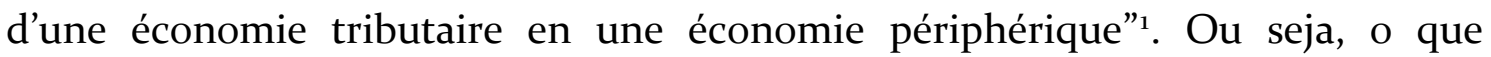
impulsionou a Independência foi a doutrina liberal do livre mercado e não a do Estado de Direito. As ideias liberais não podiam ser transpostas sem modificação do centro à periferia do capitalismo. O Brasil tornou-se independente, mas o escravismo - a principal herança colonial - continuou a exercer função nuclear na produção latifundiária: “[...] o senhor e o escravo, o latifúndio e os dependentes, o tráfico negreiro e a monocultura de exportação permaneciam iguais, em contexto local e mundial transformado" (SCHWARZ, 20oob, p. 36).

É sabido que escravismo e sistema colonial são coadunáveis. O segundo necessita do primeiro para se erigir, como já demonstrou Gilberto Freyre (1966, p. 338): “Tenhamos a honestidade de reconhecer que só a colonização latifundiária e escravocrata teria sido capaz de resistir aos obstáculos enormes que se levantaram à civilização do Brasil pelo europeu". É necessário certo senso de realismo, como o tem Fernando Novais (1989, p. 71), para perceber que, até os primórdios do século XIX, não havia nação brasileira, mas colônia de exploração portuguesa cuja produção dava-se a expensas do trabalho escravo e cuja economia destinava-se inteiramente ao mercado metropolitano. Novais prefere o uso do topônimo América Portuguesa para se referir ao protuberante empreendimento que se firmou nos trópicos com vistas à extração de matériaprima lucrativa. Em tempos de Colônia, estava justificada a escravidão como meio indispensável à acumulação de capital e ao fortalecimento do Estado português. No sistema mercantilista que vigorou entre os séculos XV e XVIII, o escravo era, segundo Florestan Fernandes (1977, p. 16), a peça-chave da rentabilidade nacional:

[...] o escravo [...] é a principal mercadoria de uma vasta rede de negócios (que vai da captura e do tráfico ao mercado de escravos e à forma de

\footnotetext{
1 "Para utilizar os conceitos correntes, os acontecimentos que se desenrolam entre $1808 \mathrm{e}$ 1850 ilustram a transformação de uma economia tributária em uma economia periférica" (Tradução nossa).
} 
trabalho), a qual conta, durante muito tempo, com um dos nervos ou a mola mestra da acumulação do capital mercantil.

Não obstante, em tempos de Independência, não encontravam as camadas dirigentes, do Império brasileiro, meios para justificar o escravismo e a dominação pessoal, pois a difusão das ideias liberais ia de encontro às práticas atrasadas que se encontravam em declínio na Europa:

\begin{abstract}
No tocante às ideias caíam em descrédito as justificações que a colonização e o Absolutismo haviam criado, substituídas agora pelas perspectivas oitocentistas do estado nacional, do trabalho livre, da liberdade de expressão, da igualdade perante a lei etc., incompatíveis com as outras, em particular com a dominação pessoal direta (SCHWARZ, 200ob, p. 36).
\end{abstract}

O fato de, no Brasil, terem convivido liberalismo e estrutura escravocrata constitui verdadeira incongruência. Mas não havia outra saída aos latifundiários que não queriam perder seus privilégios senão sustentar as práticas escravistas; delas dependia a economia nacional, uma vez que o trabalho produtivo era majoritariamente exercido pelos negros trazidos da África. Frise-se que o tráfico de escravos também não podia ser abolido, pois era fonte de enriquecimento: "O tráfico de africanos por exemplo continuou a ser um alto negócio, 'o mais lucrativo sob o sol', até a sua supressão definitiva em 1850" (SCHWARZ, 20oob, p. 37). Segundo Manolo Florentino (1997, p. 25), “o tráfico permitia superexplorar o escravo e imediatamente substituí-lo, diminuindo o intervalo entre o desembolso da compra e o seu reembolso". Assim, a escravização de pessoas incompatibilizava-se com os ideais iluministas que eclodiram no século XVIII, mas alinhava-se à finalidade do laissez-faire, qual seja, o acúmulo de capitais. No dizer de Alfredo Bosi (1992, p. 212):

\footnotetext{
Uma linguagem ao mesmo tempo liberal e escravista se tornou historicamente possível; ao mesmo tempo, refluía para as sombras do esquecimento a coerência radical ilustrada da inteligência que amadurecera no último quartel do século XVIII.
}

Foi por meio da preservação do estatuto colonial e das bases produtivas atrasadas que o Brasil se integrou à ordem capitalista vigente nos países centrais, 
onde as revoluções burguesas, inspiradas no liberalismo, puseram termo às formas aristocráticas e despóticas de governo. No entanto, a revolução burguesa brasileira significou algo bastante diverso do que ocorreu na Europa. Aqui, segundo Florestan Fernandes (2006, p. 239, grifo do autor), surgiu a modalidade político-econômica do "capitalismo dependente", que se caracteriza pela configuração incompleta e defectiva "do poder burguês e da dominação burguesa". Esse poder e essa dominação conviviam com o autoritarismo e a dominação pessoal, o que demonstra que a emancipação política significou modernização sem ruptura com o passado:

Como não há ruptura definitiva com o passado, a cada passo este se reapresenta na cena histórica e cobra o seu preço, embora sejam muito variáveis os artifícios da "conciliação" (em regra, uma autêntica negação ou neutralização da "reforma") (FERNANDES, 2006, p. 238).

Essa “conciliação" produzia, de acordo com Schwarz (200oa, p. 12, grifo do autor), uma "comédia ideológica, diferente da europeia": conciliavam-se "o instituto da escravidão" e "a prática geral do favor" com "a liberdade do trabalho, a igualdade perante a lei e, de modo geral, o universalismo". Veja-se que as ideias liberais, ao aclimatarem-se na periferia, receberam roupagem própria, deformando-se. Não podiam ser incorporadas plenamente nem ser descartadas:

\footnotetext{
No que diz respeito ao ideário liberal, encontraremos uma variação de apreciações correlata. Necessário à organização e à identidade do novo Estado e das elites, ele representa progresso. Por outro lado não expressa nada das relações de trabalho efetivas, as quais recusa ou desconhece por princípio, sem prejuízo de conviver familiarmente com elas. Daí um funcionamento especial, sem compromisso com as obrigações cognitiva e crítica do Liberalismo, o que abala a credibilidade deste último e lhe imprime, a par da feição esclarecida, um quê gratuito, incongruente e iníquo. Esta complementaridade entre instituições burguesas e coloniais esteve na origem da nacionalidade e até hoje não desapareceu por completo. (SCHWARZ, 200ob, p. 38, grifo do autor).
}

Sobre a impropriedade do liberalismo no Brasil, afirma Viotti da Costa (2010, p. 32): 
Se havia barreiras de ordem material à difusão das ideias ilustradas (analfabetismo, marginalização do povo da vida política, deficiência dos meios de comunicação), o maior entrave advinha, no entanto, da própria essência dessas ideias, incompatíveis, sob muitos aspectos, com a realidade brasileira. Na Europa, o liberalismo era uma ideologia burguesa voltada contra as Instituições do Antigo Regime, os excessos do poder real, os privilégios da nobreza, os entraves do feudalismo ao desenvolvimento da economia. No Brasil, as ideias liberais teriam um significado mais restrito, não se apoiariam nas mesmas bases sociais, nem teriam exatamente a mesma função. Os princípios liberais não se forjaram, no Brasil, na luta da burguesia contra os privilégios da aristocracia e da realeza. Foram importados da Europa. Não existia no Brasil da época uma burguesia dinâmica e ativa que pudesse servir de suporte a essas ideias. Os adeptos das ideias liberais pertenciam às categorias rurais e sua clientela. As camadas senhoriais empenhadas em conquistar e garantir a liberdade de comércio e a autonomia administrativa e judiciária não estavam, no entanto, dispostas a renunciar ao latifúndio ou à propriedade escrava. A escravidão constituiria o limite do liberalismo no Brasil.

Como se vê, o Brasil passou pelo processo paradoxal da modernização conservadora: à importação do "ideário liberal” com seus corolários progressistas somou-se a conservação do escravagismo: "A história da escravidão africana na América é um abismo de degradação e miséria que se não pode sondar, e, infelizmente, essa é a história do crescimento do Brasil" (NABUCO, 2000, p. 101).

Após a Revolução Gloriosa (1688) e a Revolução Francesa (1789), Inglaterra e França tornaram-se padrões de avanço político, científico e econômico para o mundo. Considerando que, no Brasil, segundo Machado de Assis (apud SCHWARZ, 20ooa, p. 17), “o influxo externo é que determina a direção do movimento”, as classes dirigentes modernizaram o país em conformidade com o "modelo canônico anglo-francês" (SCHWARZ, 20oob, p. 38) e isso significou assumir-se a função que cabia, no esquema de desenvolvimento do capitalismo, a uma nação de passado colonial: "às ex-colônias coube o papel de consumidores de manufaturados e fornecedores de produtos tropicais" (SCHWARZ, 20oob, p. 39). Se, aos olhos dos ingleses, escravidão e crescimento econômico eram incompatíveis, aos olhos dos brasileiros, essa combinação era natural, pois reproduzia a lógica do capitalismo periférico. Diz Gilberto Freyre (1981, p. 281): "Era pena - para o observador inglês - que, ao lado do desenvolvimento das indústrias, das artes e do comércio, continuasse o Brasil a importar negros como se importasse gado". 
Pode ser explicada, no caso brasileiro, a questão sociológica da convivência contraditória da modernidade com o atraso por meio da lei trotskista do "desenvolvimento combinado, que significa aproximação das diversas etapas, combinação das fases diferenciadas, amálgama das formas arcaicas com as mais modernas" (TROTSKY, 2017, p. 34). As nações periféricas não se desenvolvem do mesmo modo que as centrais, pois, não podendo desvencilhar-se do lastro arcaico, combinam-no com a lógica moderna do lucro e do cálculo burguês. $\mathrm{O}$ próprio processo de formação do Estado brasileiro é uma resposta às demandas econômicas mercantis, à avidez europeia de acumulação primitiva do capital. Segundo Caio Prado Júnior (1999, p. 31-32): "Se vamos à essência da nossa formação, veremos que na realidade nos constituímos para fornecer açúcar, tabaco, alguns outros gêneros; mais tarde ouro e diamantes; depois, algodão, e em seguida café, para o comércio europeu. Nada mais que isto". Se os dados estruturais da sociedade brasileira, portanto, atestam contradição, anomalia e desajuste ideológico, a realidade é que:

[...] a causa última da absurda formação social brasileira está nos avanços do capital e na ordem planetária criada por eles, de cuja atualidade as condutas disparatadas de nossa classe dominante são parte tão legítima e expressiva quanto o decoro vitoriano (SCHWARZ, 2ooob p. 39, grifo do autor).

O processo social caracterizado pela reprodução e consequente aclimatação deformante das componentes do capitalismo europeu - entre elas, a liberdade do indivíduo, do comércio, dos contratos, a primazia da racionalidade e da lei - sintetiza-se numa estrutura com caracteres que singularizam a formação do nosso país: aquelas componentes rompem com a forma clássica, doutrinária, para adequarem-se à situação política, econômica e cultural periférica, em cujo tradicionalismo assentam-se. O discurso esclarecido, por exemplo, significa incorporação do legado iluminista, embora possa, eventualmente, justificar as práticas atrasadas. É o caso, segundo Schwarz (200oa, p. 18), das instituições burocráticas oitocentistas: "embora regidas pelo clientelismo, proclamavam as formas e teorias do estado burguês moderno". Sumariamente, pode-se dizer que o liberalismo à brasileira, por ter convivido com o arbítrio - e mesmo o 
justificado -, constitui, ao mesmo tempo, elemento emancipador e excentricidade; noutras palavras: é um dado estrutural de nossa sociedade, que, embora esdrúxulo a quem olhe de fora, não deixa de ser coerente com as leis do capitalismo moderno.

Coube a Machado de Assis a desnaturalização do olhar: o autor teve a argúcia de perceber a extravagância de nossa vida social, em que estava inserido e de que extraiu a essência da Memórias póstumas. Na visão de Schwarz, o escritor carioca soube captar a singularidade das contradições sociais brasileiras, o que envolveu certa sensibilidade para intuir o arcabouço sociológico que se foi sedimentando desde os princípios da exploração colonial. Machado de Assis (1910, p. 14), consciente de que "o que se deve exigir do escritor, antes de tudo, é certo sentimento íntimo, que o torne homem do seu tempo e do seu país, ainda quando trate de assuntos remotos no tempo e no espaço", formalizou a estrutura social, isto é, transformou-a em forma literária, fê-la aparecer na composição do romance, sobretudo na figura do narrador. Se essa disposição artística de inspiração sociológica foi consciente, isso não se pode saber; a verdade é que Schwarz assim interpretou a história de Brás Cubas e pouco ou nada importa, hoje, à crítica, a intenção do autor. A obra fala por si mesma e o crítico ressalta os fatores que julga indispensáveis à interpretação. No caso de Schwarz, os histórico-sociais são-lhe esclarecedores.

Na argumentação de Schwarz, encontramos evidências de que a estrutura literária do primeiro romance realista brasileiro e a estrutura resultante da formação social do país, cujo capitalismo é dependente, possuem excepcional afinidade. Note-se que a leitura schwarziana não enfatiza o tratamento que Machado deu às questões nacionais, mas como a construção da categoria narrativa da focalização e do discurso narrativo de modo geral de certa forma apresenta-as esteticamente.

Pode-se dizer, sociologicamente, que a ideologia da classe dominante do século XIX aparecia no discurso de seus membros. Discurso afinado com as Luzes, mas que contradizia a manutenção das práticas escravistas e de cooptação. Do ponto de vista literário, o discurso do narrador é uma espécie de síntese dos discursos dos grupos elitistas. Trata-se de uma forma literária iluminadora do 
processo social sui generis, de uma imitação, por meio da linguagem artisticamente elaborada, do comportamento da classe proprietária que, consoante Schwarz (200ob, p. 40), constantemente realizava “o consumo acelerado e sumário de posturas, ideias, convicções, maneiras literárias etc., logo abandonadas por outras, e portanto desqualificadas".

O crítico mostrou que Machado deu feição literária a essa volubilidade, isto é, à maneira de ser postiça da elite oitocentista, que, por ter sido formada não numa sociedade orgânica, mas numa empresa mercantil portuguesa, foi incapaz de produzir cultura legítima, tendo buscado, ao invés disso, importar padrões estrangeiros de vivência. Isso se deve, em boa medida, à "ausência de nexo moral”, para usar as palavras de Caio Prado Júnior (1999, p. 341), tão característica do processo formativo que não foi regido por vínculos de solidariedade humana, mas por motivos de ordem econômica. Numa formação social como a nossa, fruto da aglutinação forçada de três etnias - os colonizadores portugueses, os índios e os escravos africanos - , "raças e indivíduos mal se unem, não se fundem num todo coeso: justapõem-se antes uns aos outros; constituem-se unidades e grupos incoerentes que apenas coexistem e se tocam” (PRADO JÚNIOR, 1999, p. 341). Antes de Caio Prado, Sérgio Buarque de Holanda (1976, p. 5) já havia escrito sobre essa singular "falta de coesão em nossa vida social", na qual as "iniciativas, mesmo quando se quiseram construtivas, foram continuamente no sentido de separar os homens, não de os unir".

Hoje, após os estudos de Astrojildo Pereira, Raymundo Faoro e Roberto Schwarz, o juízo de José Veríssimo (apud ROMERO, 1936, p. 26) sobre Machado de Assis, firmado na ideia de que o escritor não tratou de problemas nacionais, constitui verdadeiro equívoco: "a obra literária do Sr. Machado de Assis não pode ser julgada segundo o critério que peço licença para chamar nacionalístico”. Contrariamente ao que fez Astrojildo e Faoro, Schwarz (20oob, p. 42) não comparou a abordagem de questões políticas na Memórias póstumas com os dados historiográficos do Segundo Reinado, demonstrou, porém, que a "ambivalência ideológica das elites brasileiras" é componente essencial do discurso do narrador. Ambivalência essa caracterizada pela associação do escravismo e das variadas formas de dominação pessoal à aspiração ao ideal 
civilizatório. Schwarz (200ob, p. 42-43) designa como "norma" a cultura burguesa esclarecida e como "infração" o seu ajustamento ao arbítrio próprio à classe dominante. Segundo a interpretação dialética de Schwarz (20oob, p. 43, grifo do autor), a reversibilidade ininterrupta de infração em norma e vice-versa constitui a estrutura da sociabilidade brasileira, assim como a oscilação do narrador entre a dicção autoritária (infração) e a elocução esclarecida (norma) compõe a estrutura narrativa:

[...] além de infração, a infração é norma, e a norma, além de norma, é infração, exatamente como na prosa machadiana. Em suma, a defesa progressista do tráfico negreiro suscitava problemas ideológicos difíceis de resolver, e encarnava a parte de afetação e afronta que acompanha a vida das ideias nas sociedades escravistas modernas. A ambivalência tinha fundamento real, e Machado de Assis, conforme se verá, soube imaginar-lhe as virtualidades próximas e remotas.

Na Memórias póstumas de Brás Cubas, a forma literária contém o processo social cuja essência é a volubilidade. A conduta voltívola dos grupos dirigentes é produto da formação histórico-social específica, retardatária em face do capitalismo plenamente desenvolvido. A nossa elite, usufrutuária de cabedal, condescendente com a frouxidão moral e os acentuados antagonismos de classe, não buscou meios racionais de atenuação ou mesmo aniquilamento do servilismo e da restrição da liberdade individual. Na verdade, justificou as tendências aberrantes com base na ortodoxia liberal, deu a impressão de naturalidade às contradições mais avultosas, às práticas mais abjetas, transitando, a todo o momento, do polo civilizado ao polo da barbárie. Essa inconstância - atributo de quem é volúvel - é igualmente "um mecanismo narrativo em que está implicada uma problemática nacional”, é um "fato de composição e [...] um dispositivo literário, que fala linguagem própria" (SCHWARZ, 200ob, p. 47, grifo do autor). Noutros termos: "trata-se dos conteúdos da própria forma de prosa, presenças ubíquas e não temáticas, independentes até certo ponto das vicissitudes da ação, às quais no entanto respondem, compondo com elas um acorde de ressonância histórica e nacional profunda" (SCHWARZ, 20oob, p. 47). Perceba-se que, segundo o entendimento de Schwarz, o conteúdo - a volubilidade que qualifica a peculiaridade sociológica brasileira — está na forma. 
Dito de outro modo: o conteúdo sociológico não é tema, nem somente matéria abordada no romance, ele aparece na forma narrativa, materializado no discurso em primeira pessoa do narrador Brás Cubas.

A forma de que estamos tratando - mais propriamente, a figura do narrador — apresenta-se discursivamente do seguinte modo:

\begin{abstract}
A mudança inopinada e repetida no caráter do narrador forma a célula elementar do dispositivo literário - a volubilidade - que estamos estudando. Para o seu sujeito, no caso, o salto de uma personificação a outra comporta três satisfações ou "supremacias". Uma liga-se ao gosto pela novidade; outra ao abandono seco do modo-de-ser prévio; e a terceira à inferiorização do leitor, desnorteado e inevitavelmente em sintonia com a figura "velha", anterior, que acaba de cair (SCHWARZ, 20oob, p. 49).
\end{abstract}

Capítulo bastante elucidativo dessas características estruturais é o insigne “O delírio”. Assim Machado de Assis (1975, p. 108) o iniciou:

Que me conste, ainda ninguém relatou o seu próprio delírio; faço-o eu, e a ciência mo agradecerá. Se o leitor não é dado à contemplação destes fenômenos mentais, pode saltar o capítulo; vá direto à narração. Mas, por menos curioso que seja, sempre lhe digo que é interessante saber o que se passou na minha cabeça durante uns vinte a trinta minutos.

Esse capítulo é um excurso no interior da narrativa. Nele, é possível observar a presença das três "supremacias" de que fala Schwarz. O relato do delírio - a "representação literária de estados psíquicos aberrantes", segundo José Guilherme Merquior (1990, p. 333, grifo do autor) - atesta o "gosto pela novidade", pois “ainda ninguém relatou o seu próprio delírio". Novidade essa que não tem apenas um sentido, podendo significar o uso de uma técnica literária moderna portadora do germe do fluxo da consciência, ou mesmo introdução de associações, analogias e metáforas típicas da linguagem poética, bem como reprodução caprichosa de uma digressão que em nada contribui com o desencadeamento dos fatos, significando, antes, um capricho, uma demonstração de descompromisso com a regularidade da narração.

A recorrência ao insight é o intervalo entre a visita de Virgília ao moribundo "prestes a deixar o mundo" (ASSIS, 1975, p. 106) e a recordação do 
nascimento de Brás Cubas; trata-se de um "abandono seco do modo-de-ser prévio": entre a exposição das circunstâncias da morte e a descrição da aurora da vida, há a reminiscência de um pensamento de cunho fantástico em que a sandice ganha escoamento e a razão é abafada. O narrador, inteiramente despreocupado com a organização mental que o leitor fará da intriga, satisfaz a uma de suas veleidades, que consiste em dispor os episódios de sua vida de modo assistemático, espontâneo, avesso a regras e convenções.

"Se o leitor não é dado à contemplação destes fenômenos mentais, pode saltar o capítulo; vá direto à narração". Esse excerto revela a pressuposição de que o leitor seja desinteressado, por assim dizer, nas aventuras da mente. Se as experimentações psicológicas não lhe despertam a curiosidade, é sinal de que ele tenha inteligência limitada e seja incapaz de compreender uma reflexão que em muito contribuirá com o avanço da ciência. O narrador deduz que o leitor de suas memórias possa ser mediano, insensível à elucubração filosófica, à investigação da natureza humana. Ao mesmo tempo, Brás julga a descrição de sua viagem "à origem dos séculos" (ASSIS, 1975, p. 108) sobre o lombo de um hipopótamo, matéria refinada e iluminadora, percepção de um sujeito altamente ilustrado. Isso demonstra a sutileza do humor machadiano, em cujas variações encontramos a “inferiorização do leitor”. Outro trecho exemplificador do que estamos falando é este: "A obra em si mesma é tudo: se te agradar, fino leitor, pago-me da tarefa; se te não agradar, pago-te com um piparote, e adeus" (ASSIS, 1975, p. 98).

A volubilidade é um princípio formal que tem, para Schwarz, um caráter de classe. A maneira por que Brás Cubas narra a sua vida representa o modo de agir da classe dominante. Na Memórias póstumas, a mutabilidade ininterrupta do caráter da elite brasileira com vistas a adequar-se às conveniências, sobretudo àquelas ligadas à preservação dos privilégios assegurados pela estrutura colonial, é construída por meio das interrupções, dos subterfúgios, das tergiversações, da disposição caprichosa dos episódios, do desrespeito ao leitor, do tratamento despropositado de assuntos os mais variados etc.

\section{Referências}


ALENCASTRO, L. F. La traite negrière et l'unité nationale brésilienne. Revue Française d'Histoire d'Outre-Mer, Paris, v. 66, n. 244-245, p. 395-419, 1979.

ARANTES, P. E. Providências de um crítico literário na periferia do capitalismo. In: ARANTES, O.B.F.; ARANTES, P.E. Sentido da formação: três estudos sobre Antonio Candido, Gilda de Mello e Souza e Lúcio Costa. Rio de Janeiro: Paz e Terra, 1997. p. 7-66.

ASSIS, M. Instinto de nacionalidade. In: . Crítica. Rio de Janeiro: Garnier, 1910. p. 7-28.

Memórias póstumas de Brás Cubas. Rio de Janeiro: Civilização Brasileira; Brasília: Instituto Nacional do Livro, 1975. (Edição crítica da Academia Brasileira de Letras).

BOSI, A. A escravidão entre dois liberalismos. In: Dialética da colonização. São Paulo: Companhia das Letras, 1992. p. 194-245.

CANDIDO, A. Formação da literatura brasileira: momentos decisivos (1750-1880). 11. ed. Rio de Janeiro: Ouro sobre Azul, 2007.

COSTA, E. V. Da Monarquia à República: momentos decisivos. 9. ed. São Paulo: Ed. UNESP, 2010.

ELIOT, T. S. Tradition and the individual talent. In: Selected essays. London: Faber and Faber, 1958. p. 13-22.

FERNANDES, F. A revolução burguesa no Brasil: ensaio de interpretação sociológica. 5. ed. São Paulo: Globo, 2006.

Circuito fechado: quatro ensaios sobre o "poder institucional”. 2. ed. São Paulo: Hucitec, 1977.

FLORENTINO, M. Em costas negras: uma história do tráfico de escravos entre a África e o Rio de Janeiro (séculos XVIII e XIX). São Paulo: Companhia das Letras, 1997.

FREYRE, G. Casa-grande $\mathcal{E}$ senzala: formação da família brasileira sob o regime de economia patriarcal. 13. ed. Rio de Janeiro: José Olympio, 1966.

- Sobrados e mucambos: decadência do patriarcado rural e desenvolvimento do urbano. Rio de Janeiro: José Olympio, 1981. 
HOLANDA, S. B. Raízes do Brasil. 9. ed. Rio de Janeiro: José Olympio, 1976. (Coleção Documentos Brasileiros).

MERQUIOR, J. G. Gênero e estilo das Memórias póstumas de Brás Cubas. In: Crítica: ensaios sobre arte e literatura (1964-1989). Rio de Janeiro: Nova Fronteira, 1990. p. 331-342.

MEYER, A. Machado de Assis. 2. ed. Rio de Janeiro: Organização Simões, 1952.

NABUCO, J. O abolicionismo. Rio de Janeiro: Nova Fronteira; São Paulo: Publifolha, 200o. (Coleção Grandes Nomes do Pensamento Brasileiro).

NOVAIS, F. A. Portugal e Brasil na crise do antigo sistema colonial (1777-1808). 5. ed. São Paulo: Hucitec, 1989.

PRADO JÚNIOR, C. Formação do Brasil contemporâneo: Colônia. São Paulo: Brasiliense, 1999.

ROMERO, S. Machado de Assis. Rio de Janeiro: José Olympio, 1936.

ROUANET, S. P. Contribuição para a dialética da volubilidade. Revista USP, São Paulo, n. 9, p. 175-194, mar./ abr./ mai. 1991.

SCHWARZ, R. Ao vencedor as batatas: forma literária e processo social nos inícios do romance brasileiro. São Paulo: Duas Cidades; Ed. 34, 20ooa. (Coleção Espírito Crítico).

Complexo, moderno, nacional, e negativo. In: Que horas são? Ensaios. São Paulo: Companhia das Letras, 1987. p. 115-125. Um mestre na periferia do capitalismo: Machado de Assis. São Paulo: Duas Cidades; Ed. 34, 20oob. (Coleção Espírito Crítico).

TROTSKY, L. História da Revolução Russa. Trad. E. Huggins. Brasília: Senado Federal, 2017.

\footnotetext{
* Mestrando do Programa de Pós-Graduação em Estudos Literários da Universidade Estadual Paulista "Júlio de Mesquita Filho" - UNESP.
} 